\title{
Imaging of Cosmetic Facial Implants and Grafts
}

\author{
C.J. Schatz and D.T. Ginat
}

\begin{abstract}
SUMMARY: A wide variety of implants and grafts have been used for cosmetic facial surgery, including forehead, nose, cheek, lip, and chin augmentation. Some of the implant materials include silicone, expanded polytetrafluoroethylene (Gore-Tex), hydroxylapatite, and porous polyethylene (Medpor). Grafts include bone and cartilage, which can be prepared as "Turkish Delight" for rhinoplasty. Imaged facial implants and grafts can be encountered incidentally or purposely to evaluate complications. Many of these materials have distinct radiologic imaging features and should not be misinterpreted as pathology. Conversely, implant complications should be appropriately recognized by using a focused imaging approach. The purpose of this article was to review the different types of cosmetic facial implants and grafts with an emphasis on their expected and complicated radiologic imaging appearances.
\end{abstract}

A ccording to the American Society of Plastic Surgeons, a total of 243,777 rhinoplasty surgeries, 46,931 forehead lift surgeries, 20,680 chin augmentation surgeries, and 11,996 cheek implant surgeries were performed in the United States in 2011. ${ }^{1}$ On occasion, patients who have undergone facial augmentation procedures present for radiologic imaging. Therefore, it is important to be familiar with the common types of cosmetic facial implants and their complications. The imaging features of these implants differ on the basis of location and composition. Often, implants are used at the same time in different locations to achieve balanced proportions of facial tissues. The imaging features of commonly used material for cosmetic facial implants are reviewed in the following sections and in the Table. ${ }^{2-5}$ It is important to recognize the expected imaging appearances of implants and their complications to avoid misdiagnosing these as neoplastic processes, for instance. ${ }^{6,7}$

\section{AUGMENTATION TECHNIQUES \\ Forehead}

Cosmetic forehead augmentation (browplasty) can be performed for the treatment of frown lines and to mitigate bony deficiencies. ${ }^{8,9}$ Popular materials used in the midforehead include soft expanded

From Beverly Tower Wilshire Advanced Imaging (C.J.S.), Beverly Hills California; University of Southern California Keck School of Medicine (C.J.S.), Los Angeles, California; and Department of Radiology (D.T.G.), Massachusetts General Hospital and Harvard Medical School, Boston, Massachusetts.

Please address correspondence to Daniel T. Ginat, MD, MS, 55 Fruit St, Boston, MA 02114; e-mail: ginatd01@gmail.com

-- Indicates open access to non-subscribers at www.ajnr.org

http://dx.doi.org/10.3174/ajnr.A3214 polytetrafluoroethylene strips and silicone implants. ${ }^{7}$ The expanded polytetrafluoroethylene strips (Gore-Tex; W.L. Gore \& Associates, Newark, Delaware) are usually 1- to 2-mm thick and positioned in a vertical orientation (Fig 1). On the other hand, shield-shaped silicone implants can cover a relatively larger area, and irregular edges and perforations limit implant motion and capsular contraction. ${ }^{8}$

\section{Cheek}

Cheek augmentation (malarplasty) consists of adding volume to either the malar or submalar space or a combination of these to compensate for osseous and soft-tissue deficiencies and to elevate the cheek subcutaneous tissues. ${ }^{10-12}$ Specifically, submalar implants are positioned over the anterior walls of the maxilla (Fig 2). On the other hand, malar implants are positioned over the malar eminences and zygomatic bones in a more superior and lateral position (Fig 3). Combined malar-submalar implants span both the malar eminence and the submalar triangle.

The implants are typically inserted into the subperiosteal pocket via a transoral approach through the canine fossa. ${ }^{10}$ In the past, ovoid "button" implants were used for cheek augmentation. Currently, Silastic (Dow Corning, Auburn, Michigan) shell implants are especially popular and have characteristic crescent shapes to match the contours of the underlying anatomy. The implants are available in a variety of sizes and can be further customized intraoperatively. Small holes are sometimes incorporated into the implant to promote tissue ingrowth. In addition, the implants can be secured with sutures or screws. Other materials that have been used for midface augmentation include porous polytetrafluoroethylene (Medpor; Stryker, Allendale, New Jersey) and expanded polytetrafluoroethylene (Gore-Tex). ${ }^{10,12}$ 
Facial implant materials

\begin{tabular}{|c|c|c|}
\hline Material & Properties and Uses & Imaging Appearance \\
\hline Silicone rubber (Silastic) & $\begin{array}{l}\text { Rubber elastomer, well-tolerated and easily } \\
\text { customizable, soft pliable consistency; } \\
\text { indications: chin, lateral jaw, cheek, and nose } \\
\text { augmentation }\end{array}$ & $\begin{array}{l}\text { CT: variable attenuation, usually denser than } \\
\text { soft tissue, but less dense than bone and best } \\
\text { discerned using bone windows; } \\
\text { MRI: very low signal intensity on T1- and T2- } \\
\text { weighted sequences }\end{array}$ \\
\hline $\begin{array}{l}\text { Expanded polytetrafluoroethylene } \\
\text { (Gore-Tex) }\end{array}$ & $\begin{array}{l}\text { Biocompatible, long-lasting but can be } \\
\text { removed surgically; indications: lower face } \\
\text { lift, nasal and forehead augmentation }\end{array}$ & $\begin{array}{l}\text { CT: higher attenuation relative to soft tissues, } \\
\text { but less dense than bone; } \\
\text { MRI: hypointense to fat on T1- and T2-weighted } \\
\text { sequences }\end{array}$ \\
\hline Polytetrafluoroethylene (Teflon) & Obsolete & Imaging features similar to those of Gore-Tex \\
\hline Porous polyethylene (Medpor) & $\begin{array}{l}\text { Inert and biocompatible, low complication rate, } \\
\text { permanent; indications: lower face and nasal } \\
\text { augmentation; also used for orbital and } \\
\text { auricular reconstruction; fibrovascular } \\
\text { ingrowth can render removal difficult }\end{array}$ & $\begin{array}{l}\text { CT: attenuation between fat and water; } \\
\text { MRI: hypointense to fat on T1- and T2-weighted } \\
\text { sequences; enhancement may occur due to } \\
\text { fibrovascular ingrowth }\end{array}$ \\
\hline Hydroxylapatite & $\begin{array}{l}\text { Inert and biocompatible; blocks of } \\
\text { hydroxylapatite can allow fibrovascular } \\
\text { ingrowth and bony incorporation }\end{array}$ & $\begin{array}{l}\text { CT: hyperdense, hyperattenuation similar to } \\
\text { that of bone; the implant can become } \\
\text { incorporated into and inseparable from the } \\
\text { adjacent bone; } \\
\text { MRI: low signal on } \mathrm{Tl} \text { and T2; enhancement may } \\
\text { occur due to fibrovascular ingrowth }\end{array}$ \\
\hline Bone & $\begin{array}{l}\text { Occasionally used for rhinoplasty, cheek, and } \\
\text { chin augmentation; harvest sites include iliac } \\
\text { crest, cranium, turbinates, rib }\end{array}$ & $\begin{array}{l}\mathrm{CT} \text { : same as normal bone elsewhere; cortex and } \\
\text { trabecular can be identified unless resorption } \\
\text { has occurred } \\
\text { MRI: high } \mathrm{Tl} \text { and } \mathrm{T} 2 \text { marrow signal and low-signal } \\
\text { cortex are often discernible; in the early } \\
\text { postoperative period, marrow edema within } \\
\text { the graft may appear as low } \mathrm{Tl} \text { and high } \mathrm{T} 2 \\
\text { signal }\end{array}$ \\
\hline Cartilage & $\begin{array}{l}\text { Often used in rhinoplasty and sometimes chin } \\
\text { augmentation; harvest sites include nasal } \\
\text { septum, conchal cartilage, and costal } \\
\text { cartilage; can be part of osteochondral grafts; } \\
\text { can be diced and wrapped in Surgicel (Turkish } \\
\text { Delight) }\end{array}$ & $\begin{array}{l}\text { CT: soft-tissue density; may form a rim of } \\
\text { calcification or ossification; } \\
\text { MRI: usually low T2 and high T2 signal }\end{array}$ \\
\hline
\end{tabular}
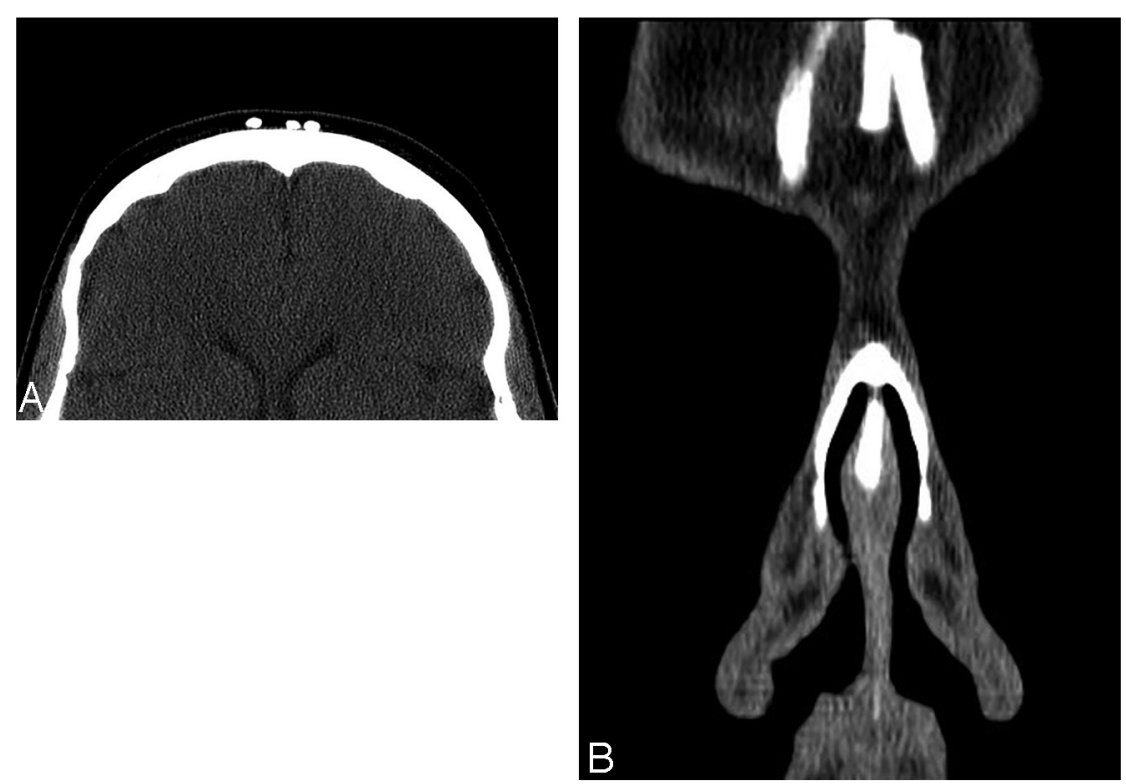

FIG 1. Forehead implants. Axial $(A)$ and coronal $(B) C T$ images show thin strips of expanded polytetrafluoroethylene in the midline of the forehead in the region of the glabella.

\section{Nasal}

Cosmetic rhinoplasty consists of altering the shape of the nose to achieve a more attractive form and relationship with the sur- rounding facial structures, while attempting to preserve the normal functions of the nose. Augmentation rhinoplasty consists of 

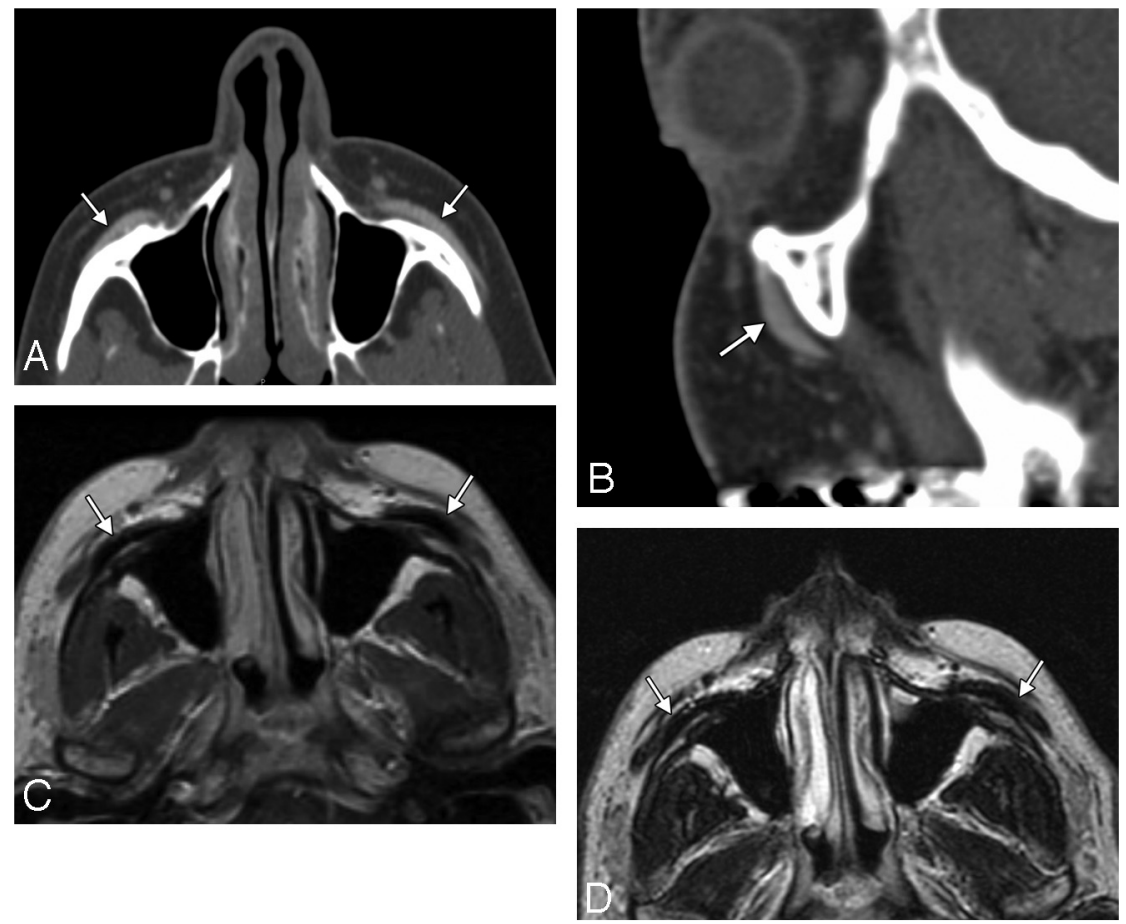

FIG 2. Malar implants. Axial $(A)$ and sagittal $(B)$ CT images show bilateral hyperattenuated silicone implants (arrows) overlying the malar eminences. The silicone implants (arrows) are hypointense on $\mathrm{Tl}(C)$ and $\mathrm{T} 2(D)$ MR images.
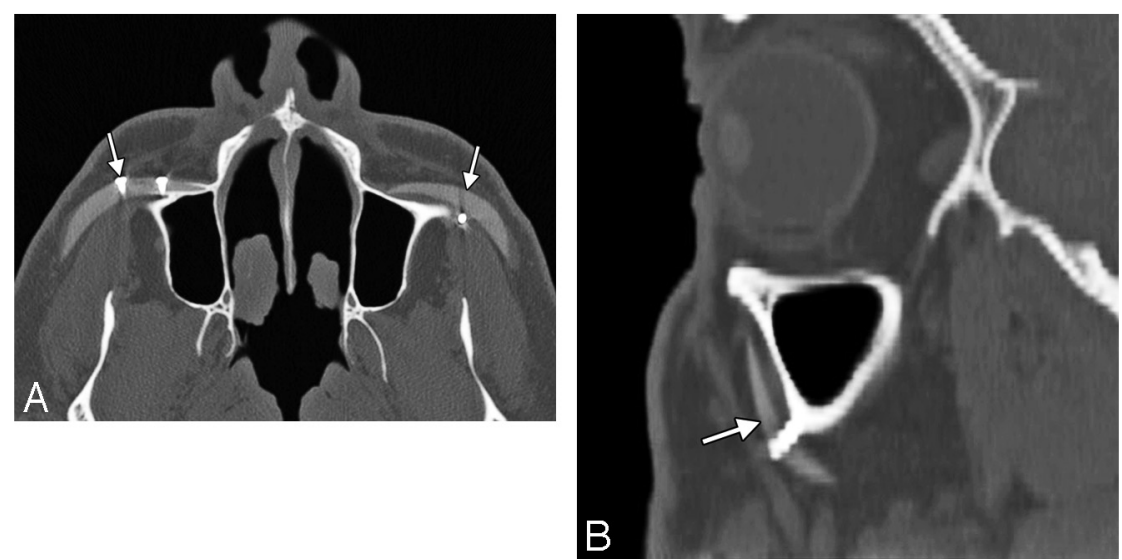

FIG 3. Submalar implants. Axial $(A)$ and sagittal $(B) C T$ images show bilateral silicone implants (arrows) secured to the underlying maxillary bone via screws.
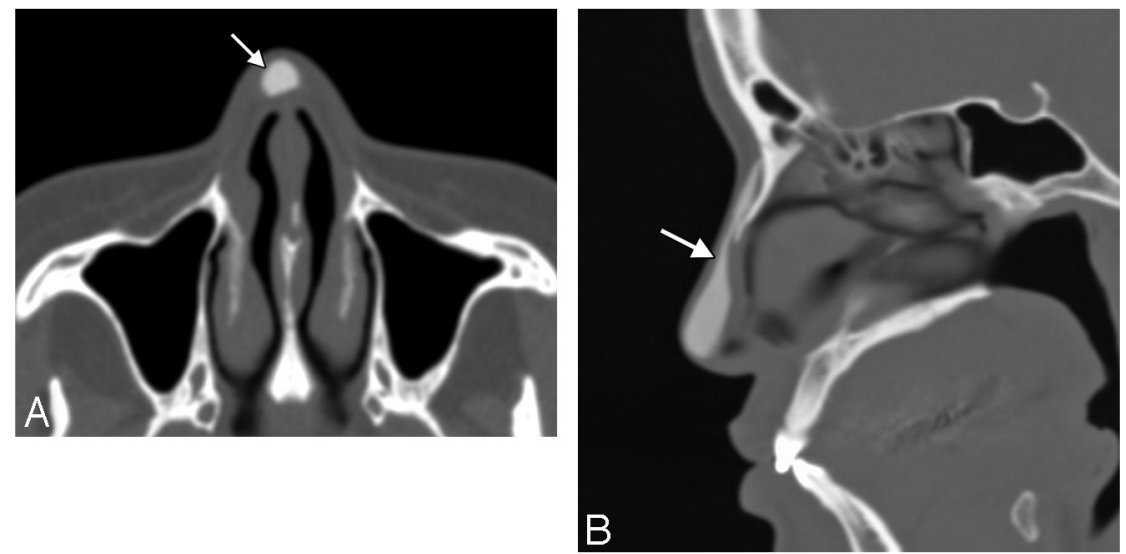

FIG 4. Rhinoplasty with a dorsal Silastic implant. Axial $(A)$ and sagittal $(B) C T$ images show the hyperattenuated implant (arrows) in the midline of the nasal dorsum. Note that the implant is thicker toward the tip than over the nasal bones. 

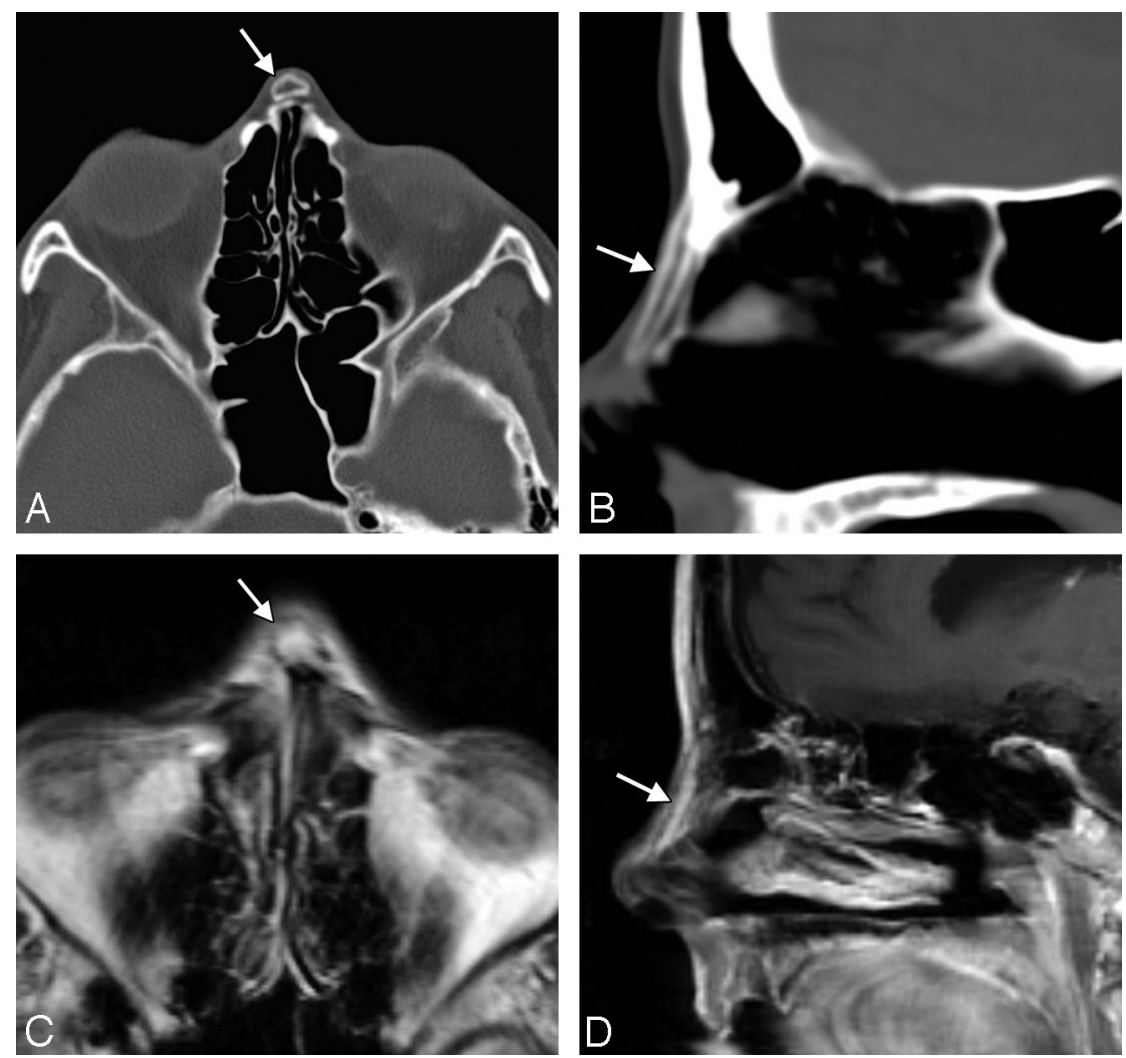

FIG 5. Rhinoplasty with a dorsal bone graft. Axial $(A)$ and sagittal $(B) C T$ images show a linear bone graft positioned along the dorsum of the nose (arrows). Axial T2 (C) and sagittal postcontrast Tl (D) MR images show hyperintense fatty marrow within the bone graft (arrows).

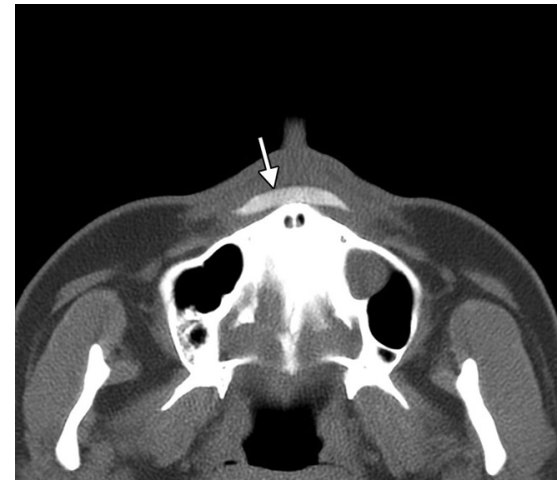

FIG 6. Premaxillary implant. Axial CT image shows a hyperattenuated silicone implant positioned anterior to the midline of the maxilla (arrow).

adding material to the nose and can be performed by using autograft, such as bone (Fig 4), or alloplastic implants, such as silicone rubber (Fig 5). ${ }^{13,14}$ Satisfactory results have also been obtained with cartilage grafts, Medpor, Gore-Tex, and Mersilene (Ethicon, Cincinnati, Ohio) mesh. ${ }^{1-18}$ "Turkish Delight" is a unique augmentation preparation used for rhinoplasty composed of diced cartilage mixed with a small amount of the patient's blood and wrapped in Surgicel (Ethicon). ${ }^{19}$ Variations of Turkish Delight, consisting of diced polyethylene, have also been used. ${ }^{17}$ Different portions of the nose can undergo augmentation, including the nasal dorsum, tip, columella, and combinations of these.

Premaxillary augmentation can be performed as an adjunct to

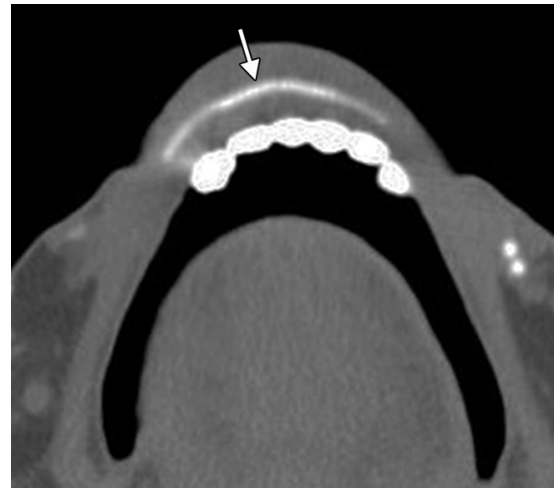

FIG 7. Lip implant. Axial CT image shows a hyperattenuated, thin, curved expanded polytetrafluoroethylene lower lip implant (arrow). Also note the presence of hyperattenuated fillers in the region of the oral commissures.

rhinoplasty to treat an excessively deep infranasal sulcus (premaxillary underprojection) and an acute nasolabial angle. ${ }^{20,21}$ This can be accomplished by using osteochondral grafts or a strip of alloplastic material, such as silicone, positioned in the midline just inferior to the anterior nasal spine of the maxilla (Fig 6). Some silicone implants have a bat-wing configuration. ${ }^{20}$

\section{Lip}

Surgical augmentation of the lips (cheiloplasty) can be performed to mitigate the changes that occur with aging, such as the development of perioral rhythides and diminished fullness and ante- 


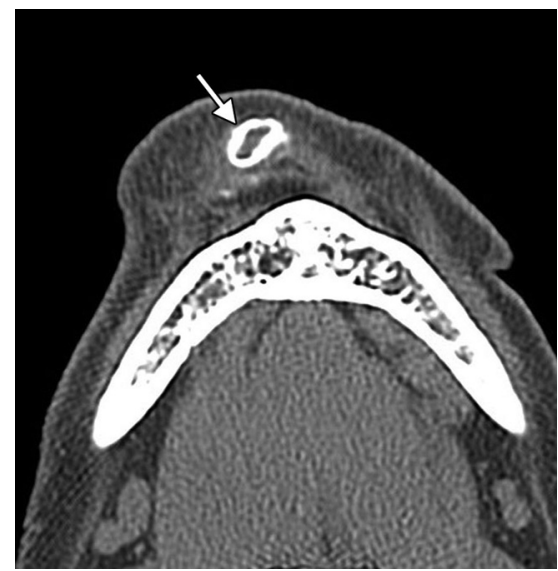

FIG 8. Chin augmentation with cartilage graft. Axial CT image shows a chunk of soft tissue with a peripheral rim of hyperattenuation (calcification or ossification) anterior to the mentum (arrow).
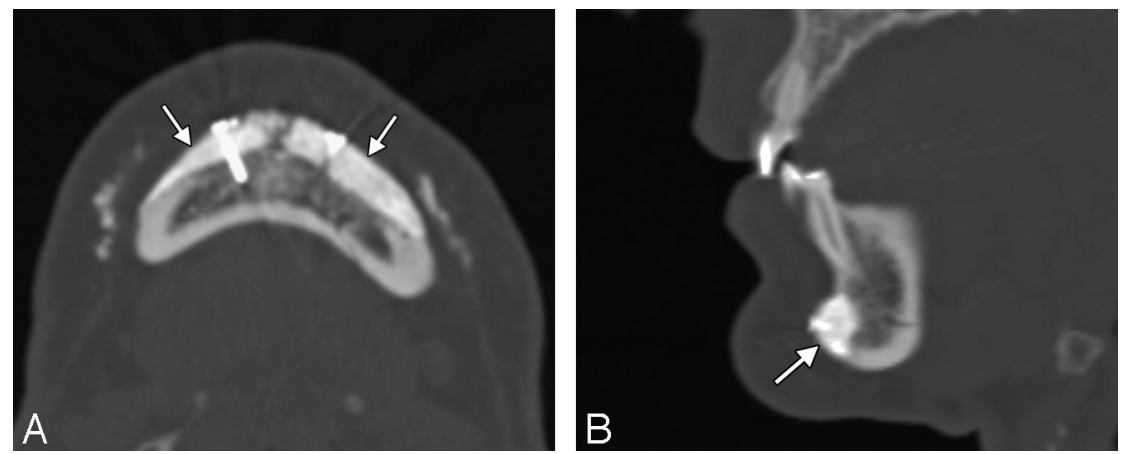

FIG 10. Chin augmentation with hydroxylapatite. Axial $(A)$ and sagittal $(B)$ CT images show the bilateral hyperattenuated implants (arrows) secured to the mandible with screws. The implant appears to have become incorporated into the underlying bone.
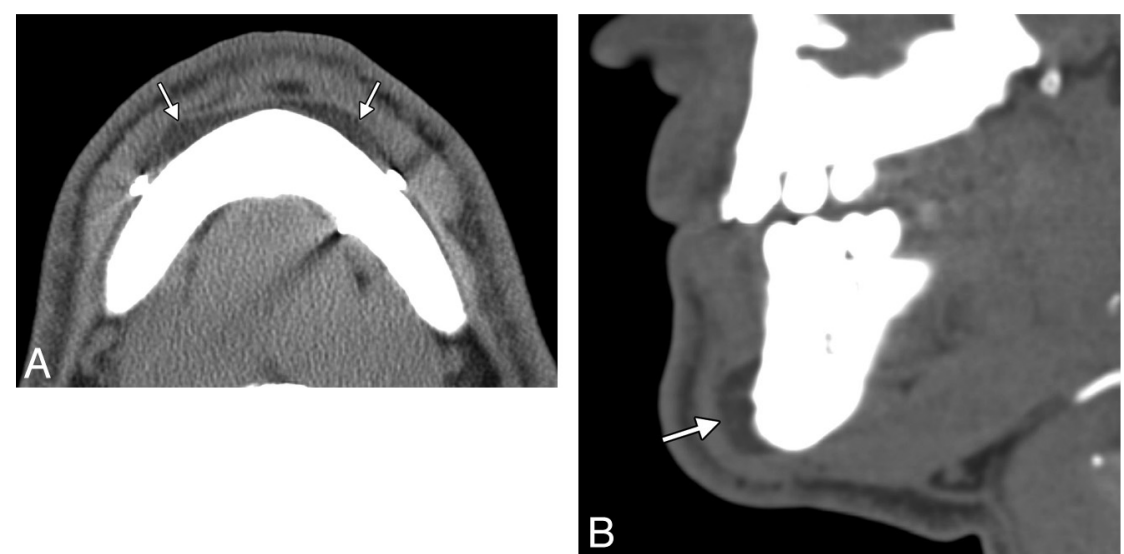

FIG 11. Chin augmentation with Medpor. Axial (A) and sagittal (B) CT images show a low-attenuation implant (arrows) anterior to the body of the mandible.

rior projection. ${ }^{22}$ Lip augmentation can also be performed in response to fashion trends, in which full lips are deemed a desirable trait. ${ }^{22}$ A variety of implants are available for lip augmentation, including fat grafts, musculoaponeurotic system grafts, acellular human dermis, and expanded polytetrafluoroethylene. ${ }^{22-25}$ These can be inserted via incisions made medial to the oral commissures and by threading the implant deep to the submucosal plane. $^{22}$ The implants are often given a trapezoidal shape, so that these are thinner laterally to conform to the natural tapering of the

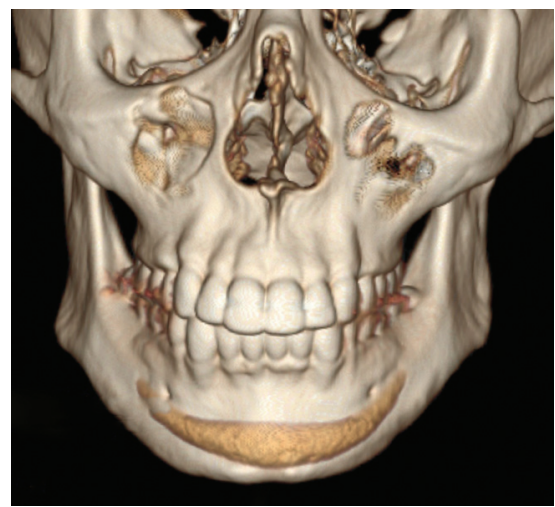

FIG 9. Chin augmentation with silicone implant. Frontal 3D CT surface rendering shows a midline crescent-shaped implant positioned inferior to the mental foramina. lips toward the oral commissures. Gore-Tex lip implants typically measure $<3 \mathrm{~mm}$ in thickness so that these are not excessively stiff. $^{24}$

\section{Chin}

Cosmetic chin augmentation (mentoplasty) can be performed to treat a deficient chin projection, which results from soft-tissue atrophy and retrusion of the mandible. ${ }^{26,27}$ Ideally the chin should extend to the level of the vermillion border of the lower lip 


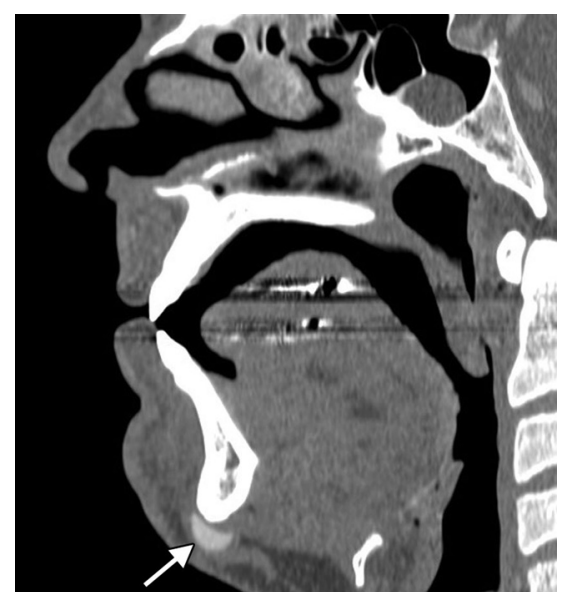

FIG 12. Submental implant. Sagittal CT image shows the hyperattenuated silicone implant (arrow) positioned inferior to the mentum.

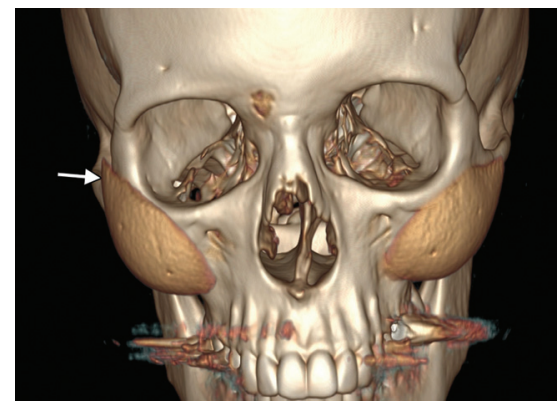

FIG 13. Implant migration. 3D CT image shows superior displacement of the right cheek implant (arrow), which occurred as a result of trauma. Compare it with the normal position of the contralateral implant.

in the sagittal plane. ${ }^{26}$ Autogenous materials, such as cartilage grafts, have been used in chin augmentation for more than a century (Fig 7). Such grafts can be readily procured during concomitant reduction rhinoplasty, for instance. However, autografts have a tendency to resorb, resulting in loss of cosmetic effect. Consequently, alloplastic chin implants, including Gore-Tex (Fig 8), Medpor (Fig 9), Silastic (Fig 10), and hydroxylapatite (Fig 11), have been introduced. ${ }^{28,29}$ Most chin implants are crescentshaped and wider centrally than laterally and are positioned approximately in the midline. Alternate designs such as cleft chin implants that are focally narrow in the midline are also available and should not be thought abnormal. Chin implants are usually

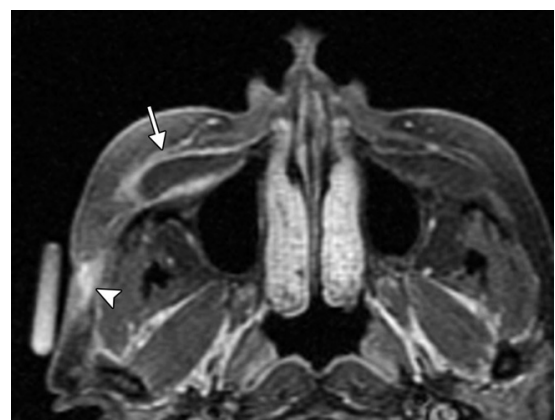

FIG 15. Implant infection. Axial fat-suppressed T1-weighted MR image shows abnormal enhancement surrounding a fluid-filled right cheek implant pocket (arrow), which extends through the right lateral cheek subcutaneous tissues to an overlying skin defect, representing a draining sinus (arrowhead). An external marker is positioned over the draining sinus.

inserted in a subperiosteal pocket anterior to the pogonion and inferior to the mental foramen.

Relatively stiff submental chin implants (Fig 12) can be inserted in conjunction with liposuction to tighten the skin and optimize the neck-chin angle. ${ }^{30}$ A variant of the chin implant is the prejowl implant, which serves to fill in a prominent prejowl sulcus and is often used in conjunction with a midface lift. ${ }^{26,27}$ The prejowl implants extend farther posteriorly and are thicker laterally compared with chin implants.

\section{COMPLICATIONS}

Essentially all cosmetic facial implants and grafts can incur complications, which include infection, migration or displacement, extrusion, foreign body reaction, heterotopic bone formation, and bone erosion. These complications often warrant imaging evaluation and subsequent surgical removal of the implants. The rate of alloplastic implant removal due to complications has been reported to be $1.9 \%-4.9 \% .{ }^{16,31}$ Imaging for early postoperative hematomas and seromas is not routinely performed unless these are larger than expected, there is an increase in size, or there are other associated complications.

Implant-related infections usually occur within the first 2 weeks of surgery and have been reported to occur in $3.2 \%$ of nasal dorsum implants, $3.8 \%$ of malar implants, and $5.3 \%$ of chin implants. $^{31,32}$ Proplast (Vitek, Valencia, California) Teflon (Dupont, Wilmington, Delaware), which is an ultraporous composite material, has fallen out of use due to the relatively high incidence
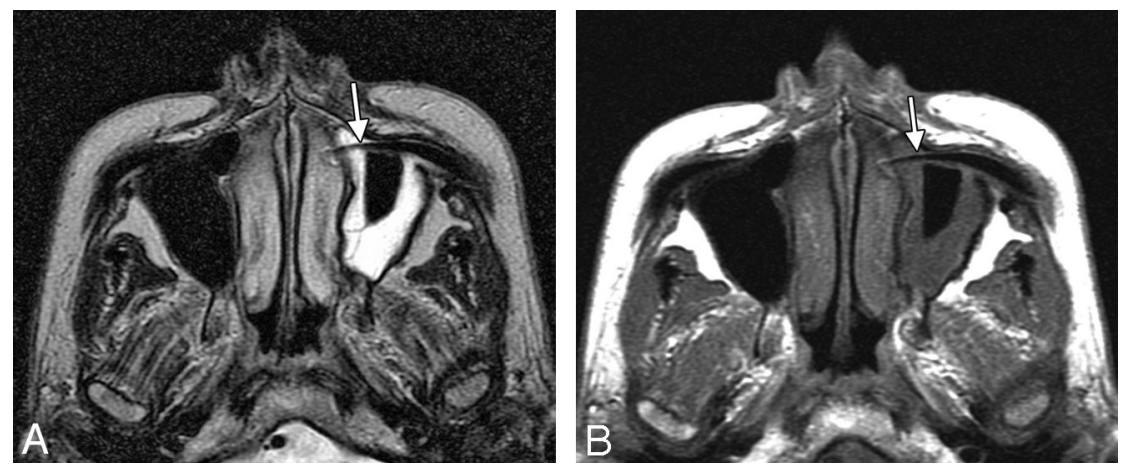

FIG 14. Implant extrusion. Axial $\mathrm{T} 2(A)$ and $\mathrm{T} 1(B)$ MR images show that the right cheek silicone implant has eroded through the anterior maxillary wall and has partially extruded into the maxillary sinus (arrow). There is associated left maxillary sinusitis. 

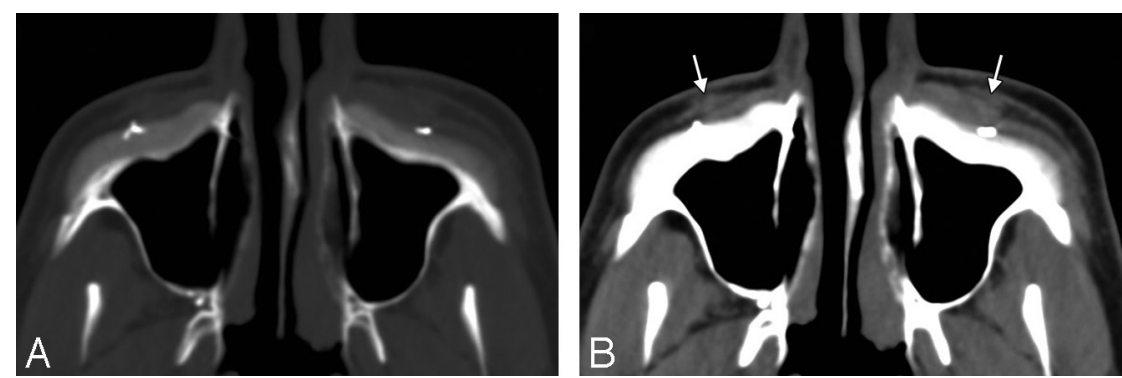

FIG 16. Cheek implant inflammation with foreign body giant cell reaction. The patient presented with bilateral cheek swelling many years after receiving the implants. Axial CT images in bone $(A)$ and soft-tissue $(B)$ windows show bilateral Proplast Teflon implants with inflammatory changes in the overlying soft tissues (arrows). Note the crude morphology of the implants, which date to the early 1990s. The implants were subsequently removed, and pathology demonstrated a combination of attenuated fibrous tissue with focal foreign body giant cell reaction and acute chronic inflammation.

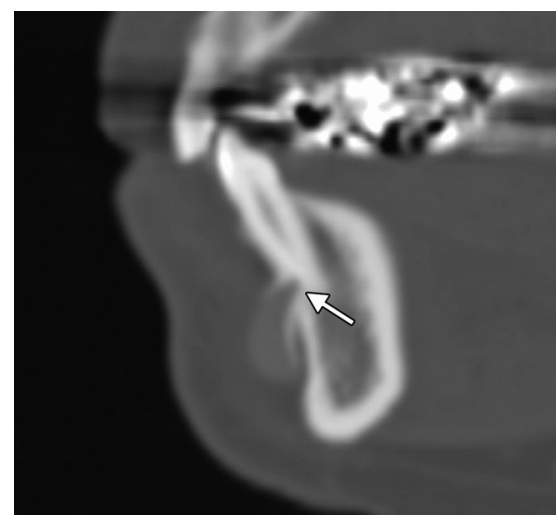

FIG 17. Chin implant bone erosion. Sagittal CT image shows that the Silastic implant has eroded through the underlying cortex, abutting the tooth apices (arrow).

of complications, such as infection, which are reported to occur in $16 \%$ of cases. ${ }^{33}$ Implant infections can manifest as cellulitis, abscess, draining sinuses, and/or osteomyelitis. MR imaging is particularly sensitive for delineating the extent of the infections, especially early in the course of disease. Fat-suppressed postcontrast T1-weighted sequences are particularly useful and often show enhancement within and surrounding the implant pocket (Fig 13). If there is incomplete fat suppression due to technical problems, short tau inversion recovery sequences can be helpful. Placement of external markers over palpable lesions and draining sinuses can facilitate determination of the necessary FOV and subsequent interpretation because the disease involvement can sometimes extend far away from the implant itself. Late infections can mimic malignancy, such as squamous cell carcinoma. ${ }^{7}$ Infections can also be associated with implant displacement and extrusion.

Chronic inflammation and foreign body giant cell reaction tend to be most exuberant with Proplast Teflon but can also be encountered with newer alloplastic implants, such as Medpor. ${ }^{33,34}$ On histology, intracytoplasmatic phagocytosis of disintegrated implant material is characteristic. Cross-sectional imaging can reveal ill-defined soft tissue surrounding the implants (Fig 14). The abnormal soft tissues can enhance and form more focal masslike areas as well.

Implant migration or displacement is an uncommon complication that can certainly result in undesirable changes in cosmesis as well as serious complications, such as scleral erosion. ${ }^{35} 3 \mathrm{D}$ CT surface renderings are particularly useful for delineating the po-

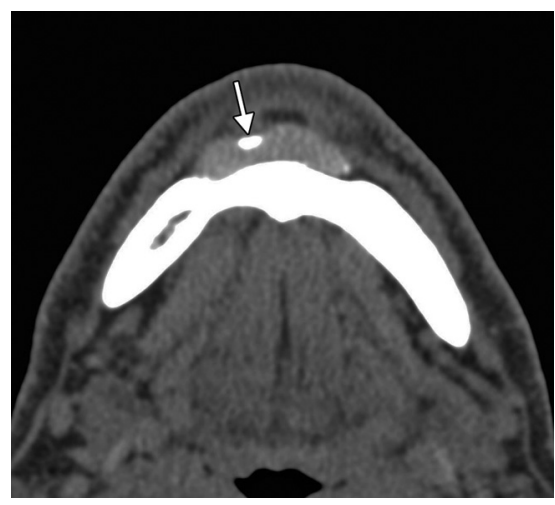

FIG 18. Chin implant heterotopic bone formation. Axial CT image shows a hyperattenuated focus along the margin of the silicone chin implant (arrow) at the expected location of the periosteal covering.

sitioning of the implants (Fig 15). Although sutures, screws, fibrous capsule formation, fibrovascular in-growth, and osseous incorporation can secure implants in position, the implants can become displaced by trauma, fluid collections, and bone erosion.

Bone erosion is a relatively frequent finding, occurring with most Silastic chin implants. ${ }^{36,37}$ The degree of erosion is usually mild and benign in nature; however, the implants can expose dental roots, resulting in pain (Fig 16). Chin implants can also erode into the mental foramen and compress the nerve. CT with dental scanning parameters is the technique of choice for evaluating symptomatic bone erosion caused by chin implants. ${ }^{36}$

Implant extrusion is a rare event that is predisposed by an underlying infection, which can make the overlying tissues relatively friable. ${ }^{38}$ Implants can extrude through the overlying skin or incision site, such as the intraoral approach for cheek implants, and even into the maxillary sinuses by eroding of the cheek implant though the anterior maxillary sinus wall (Fig 17). ${ }^{39}$

Heterotopic new bone formation is not infrequently noted adjacent to implants, particularly those in a subperiosteal location. It is usually thin and linear in a distribution corresponding to the periosteum and is of little clinical significance. ${ }^{36}$ However, heterotopic ossification is occasionally nodular (Fig 18) and can cause cosmetic deformity. ${ }^{2} \mathrm{CT}$ is the technique of choice for evaluating heterotopic ossification because some implants can display signal characteristics that are nearly identical to heterotopic bone on MR imaging. 


\section{CONCLUSIONS}

Many types of implants and grafts are now available for facial augmentation. Radiologic imaging plays an important role in the assessment of cosmetic facial implants. MR imaging and CT with multiplanar reformats and, in some cases, 3D surface renderings are useful modalities for characterizing facial implants and their complications.

\section{REFERENCES}

1. 2011 Cosmetic plastic surgery statistics. Cosmetic Procedure Trends. http://www.plasticsurgery.org/Documents/news-resources/ statistics/2011-statistics/2011-cosmetic-procedures-trendsstatistics.pdf. Accessed April 20, 2012

2. Schatz CJ, Ginat DT. Imaging of facial cosmesis. In: Ginat DT, Westesson PL, eds. Atlas of Post-Surgical Neuroradiology. Berlin, Germany: Springer-Verlag; 2012. In press

3. Ginat DT, Schatz CJ. Imaging features of midface injectable fillers and associated complications. AJNR Am J Neuroradiol. 2012 Jul 26 [Epub ahead of print]

4. Coskun U, Ozturk S, Zor F, et al. Imaging of porous polyethylene implant by using multidetector spiral computed tomography. $J$ Craniofac Surg 2008;19:156-58

5. Galluzzi P, De Francesco S, Giacalone G, et al. Contrast-enhanced magnetic resonance imaging of fibrovascular tissue ingrowth within synthetic hydroxyapatite orbital implants in children. Eur J Ophthalmol 2011;21:521-28

6. Gonçales ES, Almeida AS, Soares S, et al. Silicone implant for chin augmentation mimicking a low-grade liposarcoma. Oral Surg Oral Med Oral Pathol Oral Radiol Endod 2009;107:e21-23

7. Bain CJ, Odili J. Late infection of an alloplastic chin implant masquerading as squamous cell carcinoma. J Plast Reconstr Aesthet Surg 2012; 65:e151-52

8. Wong JK. Forehead augmentation with alloplastic implants. Facial Plast Surg Clin North Am 2010;18:71-77

9. Mandel MA. Treatment of glabellar frown lines using silicone implants. Ann Plast Surg 1991;27:110-04

10. Binder WJ, Azizzadeh B. Malar and submalar augmentation. Facial Plast Surg Clin North Am 2008;16:11-32, v

11. Binder WJ. Facial rejuvenation and volumization using implants. Facial Plast Surg 2011;27:86-97

12. Matros E, Momoh A, Yaremchuk MJ. The aging midfacial skeleton: implications for rejuvenation and reconstruction using implants. Facial Plast Surg 2009;25:252-59

13. Ward JL, Garri JI, Wolfe SA. The osseous genioplasty. Clin Plast Surg 2007;34:485-500

14. Erlich MA, Parhiscar A. Nasal dorsal augmentation with silicone implants. Facial Plast Surg 2003;19:325-30

15. Gentile P, Cervelli V. Nasal dorsum reconstruction with 11 th rib cartilage and auricular cartilage grafts. Ann Plast Surg 2009;62: 63-66

16. Conrad K, Torgerson CS, Gillman GS. Applications of Gore-Tex implants in rhinoplasty reexamined after 17 years. Arch Facial Plast Surg 2008;10:224-31

17. Richardson S, Agni NA, Pasha Z. Modified Turkish delight: mor- cellized polyethylene dorsal graft for rhinoplasty. Int J Oral Maxillofac Surg 2011;40:979-82

18. Berghaus A, Stelter K. Alloplastic materials in rhinoplasty. Cur Opin Otolaryngol Head Neck Surg 2006;14:270-77

19. Erol OO. The Turkish delight: a pliable graft for rhinoplasty. Plast Reconstr Surg 2000;105:2229-41, discussion 2242-43

20. Fanous N, Yoskovitch A. Premaxillary augmentation: adjunct to rhinoplasty. Plast Reconstr Surg 2000;106:707-12

21. Kim WS, Kim CH, Yoon JH. Premaxillary augmentation using autologous costal cartilage as an adjunct to rhinoplasty. J Plast Reconstr Aesthet Surg 2010;63:e686-90

22. Byrne PJ, Hilger PA. Lip augmentation. Facial Plast Surg 2004;20:31-38

23. Hanke CW. A new ePTFE soft tissue implant for natural-looking augmentation of lips and wrinkles. Dermatol Surg 2002;28:901-08

24. Linder RM. Permanent lip augmentation employing polytetrafluoroethylene grafts. Plast Reconstr Surg 1992;90:1083-90, discussion 1091-92

25. Clymer MA. Evolution in techniques: lip augmentation. Facial Plast Surg 2007;23:21-26

26. Shire JR. The importance of the prejowl notch in face lifting: the prejowl implant. Facial Plast Surg Clin North Am 2008;16:87-97, vi

27. Romo T, Yalamanchili $H$, Sclafani AP. Chin and prejowl augmentation in the management of the aging jawline. Facial Plast Surg 2005;21:38-46

28. Choe KS, Stucki-McCormick SU. Chin augmentation. Facial Plast Surg 2000;16:45-54

29. Cottrell DA, Wolford LM. Long-term evaluation of the use of coralline hydroxyapatite in orthognathic surgery. J Oral Maxillofac Surg 1998;56:935-41, discussion 941-42

30. Newman J, Dolsky RL, Mai ST. Submental liposuction extraction with hard chin augmentation. Arch Otolaryngol 1984;110:454-57

31. Wang TD. Multicenter evaluation of subcutaneous augmentation material implants. Arch Facial Plast Surg 2003;5:153-54

32. Niamtu J 3rd. Essentials of cheek and midface implants. J Oral Maxillofac Surg 2010;68:1420-29

33. Whear NM, Cousley RR, Liew C, et al. Post-operative infection of Proplast facial implants. Br J Oral Maxillofac Surg 1993;31:292-95

34. Gosau M, Draenert FG, Ihrler S. Facial augmentation with porous polyethylene (Medpor): histological evidence of intense foreign body reaction. J Biomed Mater Res B Appl Biomater 2008;87:83-87

35. Menon V, Gupta H. An unusual complication of malar augmentation: transconjunctival exposure and scleral erosion. Ophthal Plast Reconstr Surg 2012;28:e7-9

36. Abrahams JJ, Caceres C. Mandibular erosion from Silastic implants: evaluation with a dental CT software program. AJNR Am J Neuroradiol 1998;19:519-22

37. Matarasso A, Elias AC, Elias RL. Labial incompetence: a marker for progressive bone resorption in Silastic chin augmentation. Plast Reconstr Surg 1996;98:1007-14, discussion 1015

38. Graham BS, Thiringer JK, Barrett TL. Nasal tip ulceration from infection and extrusion of a nasal alloplastic implant. J Am Acad Dermatol 2001;44:362-64

39. Adams JR, Kawamoto HK. Late infection following aesthetic malar augmentation with Proplast implants. Plast Reconstr Surg 1995;95:382-84 